\title{
Treatment of ulcerative colitis in the cottontop tamarin using antibody to tumour necrosis factor alpha
}

\author{
P E Watkins, B F Warren, S Stephens, P Ward, R Foulkes
}

\begin{abstract}
Background-The aetiology and pathophysiology of ulcerative colitis remains unclear; however, there is increasing recognition of the critical role of inflammatory cytokines in the pathogenesis of this disease. Among these, tumour necrosis factor $\alpha$ (TNF $\alpha)$ seems to play an important role.

Aim-To study the effects of an engineered human monoclonal antibody to TNF $\alpha$ (CDP571) in the treatment of idiopathic ulcerative colitis in the cottontop tamarin.

Methods-Six cottontop tamarins with confirmed ulcerative colitis received repeated doses of CDP571. Progression of disease was assessed by measuring both body weight and rectal biopsy pathology. Results-All animals showed a rapid improvement in clinical condition and rectal biopsy pathology that was maintained following completion of the therapy.

Conclusion-These studies indicate the efficacy of selective antibody therapy to TNF $\alpha$ for the treatment of ulcerative colitis in a primate and suggest that similar therapy in humans could be of value.

(Gut 1997; 40: 628-633)
\end{abstract}

Keywords: ulcerative colitis, cottontop tamarin, antibody to tumour necrosis factor $\alpha$.

The term inflammatory bowel disease (IBD) encompasses two chronic disorders affecting all or part of the gastrointestinal tract. These are Crohn's disease and ulcerative colitis. For both diseases the causative agent is unclear. Proposed aetiologies include infectious agents, ${ }^{12}$ response to measles vaccination, ${ }^{3}$ vascular disruptions, ${ }^{4}$ and disorders of the immune system. Furthermore, there is increasing evidence of a genetic susceptibility to these diseases, which may act alone or perhaps in association with environmental factors. ${ }^{5}$

Ulcerative colitis and Crohn's disease both demonstrate characteristic clinicopathological features. A central feature is the local inflammatory response in the gut wall which is characterised by an influx of T-lymphocytes and other mononuclear cells, especially macrophages. ${ }^{6}$ In recent years, numerous cytokines have been implicated as being crucial to the disease processes, including tumour necrosis factor $\alpha(\mathrm{TNF} \alpha)$, interleukin (IL) 6 , IL- $1 \beta,{ }^{7}$ and platelet activating factor (PAF) ${ }^{8}$ However, the significance of individual cytokines has often been difficult to elucidate from clinical studies. At times, investigators have failed to show a consistent alteration in cytokine production or release in IBD. Furthermore, in patients receiving treatment, certain treatments - for example, 5-aminosalicylic acid or corticosteroids, or both, will cause a reduction in the concentrations of numerous cytokines in the colonic mucosa. ${ }^{9}$ More recently, the development of specific antibodies to cytokines such as $\mathrm{TNF} \alpha$ has provided the opportunity to assess the possible roles of individual cytokines in the disease state both in animal models and in humans.

$\mathrm{TNF} \alpha$ is a cytokine released by activated mononuclear cells and $\mathrm{T}$ cells. It seems to have a clinically important role in septic shock ${ }^{10}$ and in rheumatoid arthritis. ${ }^{11}$ In the latter condition selective blockade of TNF $\alpha$ by monoclonal antibodies will ameliorate the disease process. ${ }^{12}$ In addition, TNF $\alpha$ has been implicated in the pathogenesis of IBD. Raised concentrations of TNF $\alpha$ have been noted in the serum $^{13}$ and increased TNF $\alpha$ immunoreactivity has been shown in the lamina propria of patients with active Crohn's disease or ulcerative colitis. ${ }^{14}$ Furthermore, it has been shown that there are significant increases in faecal $\mathrm{TNF} \alpha$ concentrations in patients with active IBD. ${ }^{15}$

A large number of animal models of IBD have been described and many have been reviewed previously. ${ }^{16}$ In most cases the models are solely of colonic inflammation, not of IBD. Inflammation is often induced by the local application of an irritant, such as acetic acid, to the colon, in some cases with prior sensitisation of the animal to the irritant material. Although these approaches can be used to study various aspects of colonic inflammation, the resulting pathology shows few, if any, similarities to that seen in human IBD. Moreover, the pathological changes invariably improve once the insult has been removed, unlike the situation in humans. None the less, in a rodent model of colonic inflammation a beneficial response was noted after administration of a selective monoclonal antibody directed against TNF $\alpha .{ }^{17}$

The cottontop tamarin, a small, new world primate, is unique among animal models of IBD in that it develops a spontaneous form of colitis which shows many similarities to the condition of ulcerative colitis in humans Animals present clinically with chronic diarrhoea and weight loss and may die from the \\ 23 December 1996
}


condition if untreated. Both the pathology and the response to therapy with 5-aminosalicylic acid compounds, in some cases combined with corticosteroids, show close similarities to the condition in humans. ${ }^{1819} \mathrm{~A}$ unique feature of the disease in the cottontop tamarin is the development of secondary complications, namely colonic adenocarcinoma ${ }^{20}$ and sclerosing cholangitis, ${ }^{21}$ which are also seen in human ulcerative colitis. Also, we have recently demonstated a significant increase in faecal $\mathrm{TNF} \alpha$ concentrations in cottontop tamarins with active colitis, ${ }^{22}$ illustrating a further similarity to the condition in humans.

The cottontop tamarin has been used before to evaluate potential therapeutic regimens for treating ulcerative colitis. These trials have included use of murine monoclonal antibodies against the adhesion molecules E-selectin and $\alpha 4$ integrin. ${ }^{23}$

In this study the effect of an engineered monoclonal antibody against human $\mathrm{TNF} \alpha$ (CDP571) was assessed in spontaneous ulcerative colitis in the cottontop tamarin. The study was divided into two sections: first, the pharmacokinetics of CDP571 were evaluated in two normal animals; and, second, a trial using CDP571 for treatment of ulcerative colitis in the cottontop tamarin was undertaken. This study was planned and executed in a similar way to an "open" clinical trial. This was because of the comparative scarcity of the amimals (which are listed as endangered under the Conference on International Trade of Endangered Species (CITES)). No animals received placebo as an historical evaluation of colony health records showed that animals with confirmed ulcerative colitis which did not receive effective therapy continued to lose weight and showed further deterioration in their rectal biopsy pathology.

\section{Methods}

ANIMALS

All animals used in this study were captive bred at the University of Bristol colony. They were housed under standard environmental conditions as described previously. ${ }^{24} 25$ Animals were fed a complete pelleted diet (New World Primate diet, SDS Diets) and this was supplemented with fresh fruit each day. In addition, animals received regular supplementation with vitamin D3 administered orally.

Two animals were recruited to the pharmacokinetic study. Both appeared clinically normal and they were confirmed to be free of rectal pathology by histological examination of

TABLE I Details of animals recruited to second part of the study

\begin{tabular}{lll}
\hline Animal & Sex & Age at entering study \\
\hline B221 & Male & 16 months \\
B213 & Male & 15 months \\
B201 & Male & 23 months \\
B111 & Male & 86 months \\
R194 & Female & 23 months \\
R192 & Female & 27 months \\
\hline
\end{tabular}

a rectal biopsy specimen taken before recruitment. Six cottontop tamarins were recruited to the second phase of the study (Table I). All animals had confirmed ulcerative colitis, based on their clinical history of diarrhoea and weight loss, endoscopic examination of the colon along with histopathological examination of a rectal biopsy specimen taken at that time. Faecal samples were taken from the animals for culture to eliminate any known faecal pathogens. None of the six animals recruited to the study had received previous treatment for colitis.

\section{MONOCLONAL ANTIBODY}

\section{Generation of the antibody}

The antibody used in this study (CDP571) is derived from a murine monoclonal antibody to recombinant human $\mathrm{TNF} \alpha$ which has been engineered to contain human $\mathrm{g} 4$ and $\kappa$ light chain constant regions with Eu frameworks as described previously. ${ }^{27}$

\section{Pharmacokinetics}

Two animals received a single dose of CDP571 at $20 \mathrm{mg} / \mathrm{kg}$ by intramuscular injection. To administer the antibody, animals were sedated by an intramuscular injection of ketamine hydrochloride (Vetalar, Parke Davies; 20-25 $\mathrm{mg} / \mathrm{kg}$ ). Blood samples (maximum volume 0.5 $\mathrm{ml}$ into EDTA tubes) were taken from these animals before injection and at eight and 24 hours, and two, three, five, seven, 10, 14, 21 , and 28 days after administration of CDP571. Samples were centrifuged and plasma stored at $-70^{\circ} \mathrm{C}$ pending analysis for CDP571 and antibodies to CDP571.

\section{Therapeutic protocol}

Animals recruited to the study received CDP571 at a dose of $20 \mathrm{mg} / \mathrm{kg}$ every six days for a total of six doses. CDP571 was injected, by deep intramuscular injection, into the quadriceps femoris muscle under anaesthesia as described earlier (Table II).

EVALUATION OF RESPONSE TO TREATMENT Standard indicators of disease progression in the cottontop tamarin were used to evaluate response to treatment. These were clinical signs, body weight and histopathological examination of rectal biopsy specimens taken on

\begin{tabular}{llll} 
TABLE II & Outline of protocol & \\
\hline Day & CDP571 & Biopsy & Blood sample \\
\hline-3 & & + & + \\
0 & dose & & \\
6 & dose & + & + (pre-drug) \\
12 & dose & + & \\
18 & dose & & + \\
24 & dose & & + \\
25 & & & + \\
30 & dose & + & + \\
32 & & + & + \\
63 & & + & +
\end{tabular}


TABLE III Histology scoring system ${ }^{26}$

\begin{tabular}{llll}
\hline Acute pathology & Score & Chronic pathology & Score \\
\hline Polymorphonuclear cells in lamina propria & 1 & Mild chronic inflammation & 1 \\
Polymorphonuclear cells in crypt epithelium & 2 & Severe chronic inflammation & 2 \\
Crypt abscess & 3 & & \\
Crypt destruction & 4 & & \\
Overall maximum score & 6 & & \\
\hline
\end{tabular}

days $12,32,49$, and 63 . Biopsy specimens were evaluated by a pathologist using an objective scoring system developed from one used previously for assessing human rectal specimens (Table III). ${ }^{26}$ Specimens were graded from 0 (normal) to 6 (severe active disease) on the basis of inflammatory cell infiltrate, crypt architecture and mucosal disruption (Fig 1).

Biopsy scores and body weights before and after CDP571 treatment were compared using the Friedman non-parametric repeated measures test. Differences were considered significant when $\mathrm{p}<0.05$.

Blood samples were also taken when the animals were sedated for other procedures that is, on days $12,25,32,49$, and 63 , to permit measurement of plasma concentrations of CDP571 and of host antibodies to CDP571.
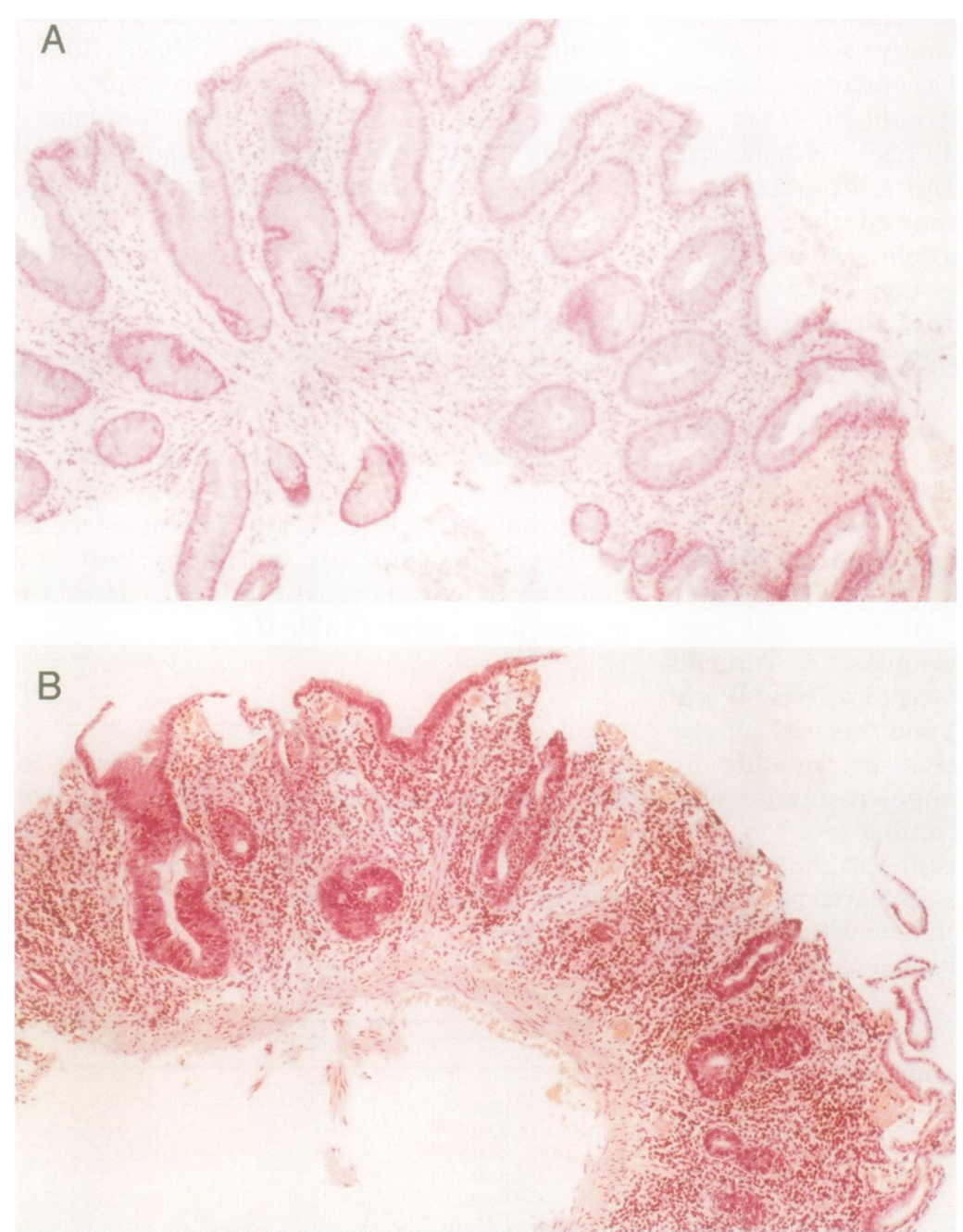

Figure 1: Representative histology of rectal biopsy specimens. (A) Grade 1 specimen with intact epithelium with few polymorphonuclear cells in the lamina propria. (B) Grade 5 specimen showing loss of epithelium, crypt destruction and infiltration of acute and chronic inflammatory cells.
ELISAS FOR CDP571 AND ANTIBODIES TO CDP571 ELISA techniques were used as described previously. ${ }^{27}$ Briefly, for the pharmacokinetic assay, diluted plasma samples were added to microtitre plates coated with $\operatorname{rhTNF} \alpha$ and bound CDP571 was revealed with mouse antihuman IgG4 (Serotec) followed by horseradish peroxidase (HRP) conjugated goat anti-rabbit IgG (Jacksons Laboratories). Bound HRP was revealed using TMB substrate and colour development as proportional to the amount of CDP571 in the sample.

Antibodies to CDP571 were detected using a double antigen sandwich ELISA system. Plasma samples (diluted 1 in 10 in phosphate buffered saline) $/ 1 \%$ bovine serum albumin (BSA)) were added to CDP571 coated plates and the sandwich was completed with CDP571 conjugated to HRP, followed by TMB substrate. An affinity purified rabbit hyperimmune serum was used as a standard and results expressed as units/ml ( 1 unit being equivalent to $1 \mathrm{mg} / \mathrm{ml}$ of the rabbit standard).

\section{Results}

PHARMACOKINETIC STUDY

Figure 2 shows the plasma elimination profiles for the two animals. Analyses demonstrated that CDP571 was cleared from normal tamarins with a half-life of around six days (5.8 and $7 \cdot 0$ days). By day 28 , there was little host antibody response to CDP571. Therefore, the drug was administered every six days in the therapeutic protocol.

RESPONSE TO TREATMENT

None of the animals showed any adverse effects to repeated dosing with CDP571, either locally or systemically.

Analysis of plasma samples confirmed that during the treatment period, CDP571 concentrations continued to reach circulating levels in excess of $100 \mu \mathrm{g} / \mathrm{ml}$ (range $51 \cdot 4-227 \cdot 8 \mu \mathrm{g} / \mathrm{ml}$; Table IV) and remained in circulation for several weeks (geometric mean of $0.5 \mu \mathrm{g} / \mathrm{ml}$ and range of $0 \cdot 05-6.5 \mu \mathrm{g} / \mathrm{ml}$ at day 49$)$. No immune response to the antibody was detected during the treatment period, although low levels of antibodies to CDP571 (3-9 units/ml) were seen in four of the six animals when CDP571 was cleared from the circulation after the final dose.

All animals showed a clinical response to treatment and in all cases there was an improvement in faecal quality after starting treatment. Figure 3 shows changes in body weight. Mean body weight rose following the first dose of antibody and remained significantly elevated during the treatment period and during the following month $(+33.3(10) \mathrm{g}$ (mean $(\mathrm{SEM})$ ) at day 63, p<0.05). This represents an increase of around $6 \%$ compared with pre-entry body weight and was maintained throughout the study.

Examination of rectal biopsy specimens showed a rapid fall in mean rectal biopsy score after starting treatment (Table $\mathrm{V}$ ), indicating a 


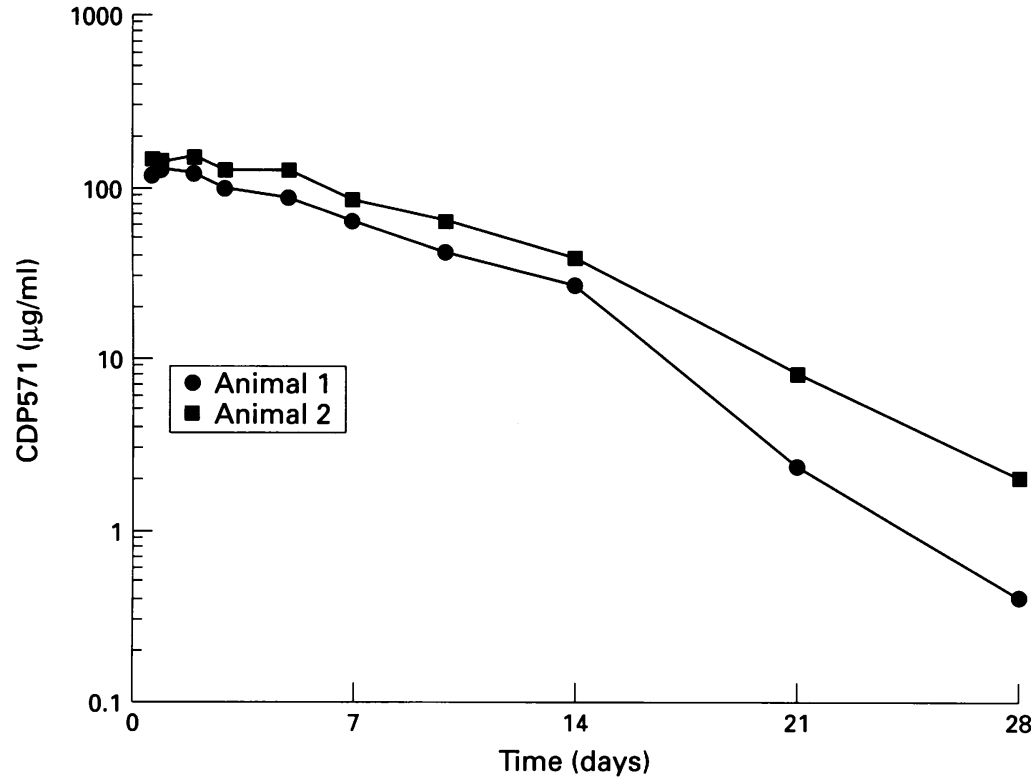

Figure 2: Plasma clearance profile of CDP571 in two cottontop tamarins after a single intramuscular injection of $20 \mathrm{mg} / \mathrm{kg}$. Values are individual plasma concentrations.

TABLE IV Plasma concentrations of CDP571 $(\mu \mathrm{g} / \mathrm{ml})$

\begin{tabular}{|c|c|c|c|c|c|c|c|c|}
\hline \multirow{2}{*}{$\begin{array}{l}\text { Time after } \\
\text { first dose } \\
\text { (days) }\end{array}$} & \multirow{2}{*}{$\begin{array}{l}\text { Dose no./days } \\
\text { after administration } \\
\text { of CDP571 }\end{array}$} & \multicolumn{6}{|c|}{ Animal number } & \multirow{2}{*}{$\begin{array}{l}\text { Geometric } \\
\text { mean }\end{array}$} \\
\hline & & $R 192$ & $R 194$ & $B 111$ & $B 201$ & $B 213$ & $B 221$ & \\
\hline $\begin{array}{l}-3 \\
12 \\
25 \\
32 \\
49 \\
63\end{array}$ & $\begin{array}{l}\text { Before } \\
2 / 6 \\
5 / 1 \\
6 / 2 \\
6 / 19 \\
6 / 33\end{array}$ & $\begin{array}{c}0 \cdot 05^{\star} \\
64 \cdot 7 \\
51 \cdot 4 \\
6 \cdot 3 \\
0.05 \\
0.05\end{array}$ & $\begin{array}{c}0.05 \\
166 \cdot 5 \\
214 \cdot 0 \\
172 \cdot 5 \\
4 \cdot 2 \\
0.05\end{array}$ & $\begin{array}{c}0.05 \\
67 \cdot 2 \\
105 \cdot 7 \\
57 \cdot 9 \\
0.84 \\
0.05\end{array}$ & $\begin{array}{c}0.05 \\
66 \cdot 1 \\
149 \cdot 1 \\
68 \cdot 0 \\
0.31 \\
0.05\end{array}$ & $\begin{array}{l}0.05 \\
62.0 \\
\text { NT } \\
37.2 \\
0.05 \\
0.05\end{array}$ & $\begin{array}{c}\text { NT } \\
90 \cdot 6 \\
227 \cdot 8 \\
154 \cdot 5 \\
6 \cdot 5 \\
1 \cdot 21\end{array}$ & $\begin{array}{c}0.05 \\
80.3 \\
131.6 \\
53.9 \\
0.5 \\
0.1\end{array}$ \\
\hline
\end{tabular}

${ }^{\star}$ Limit of detection of $0.05 \mu \mathrm{g} / \mathrm{ml}$. $\mathrm{NT}=$ not tested.

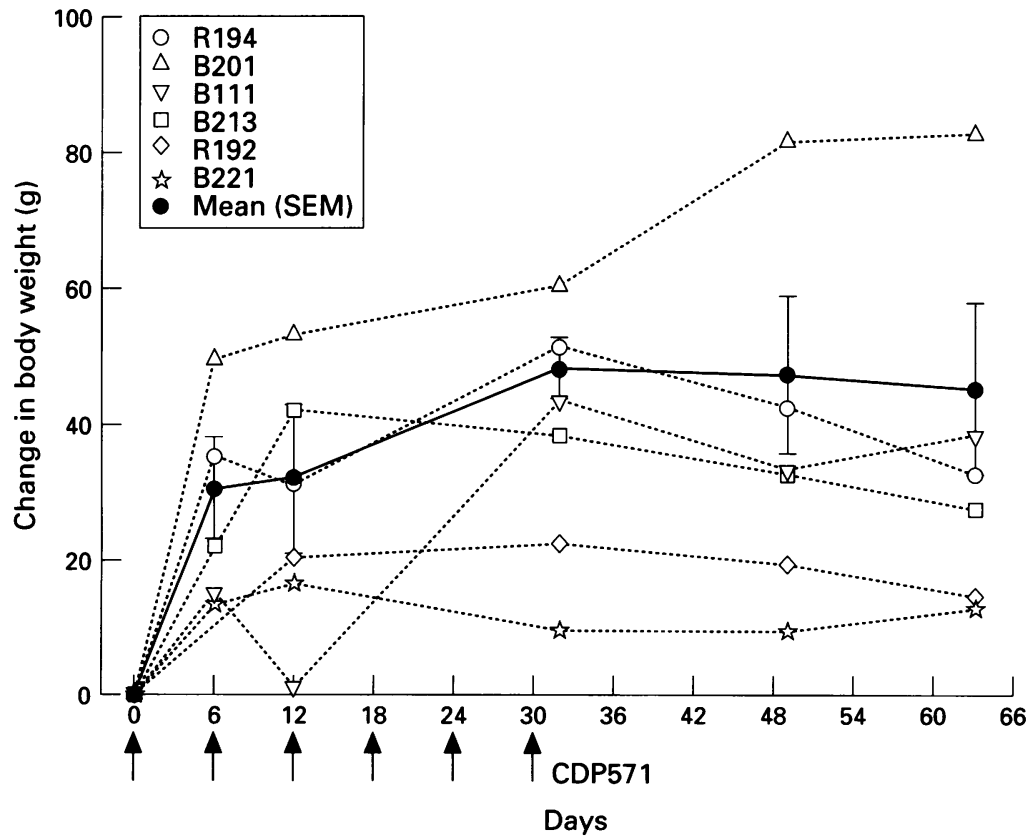

Figure 3: Changes in body weight for individual animals and the mean (SEM) (solid circles) value in cottontop tamarins given a course of CDP571 treatment ( $6 \times 20 \mathrm{mg} / \mathrm{kg})$.

reduction in disease activity. At day 12 , there was already a statistically significant reduction in biopsy score compared with day 0 , which by the end of treatment had fallen from a pre-entry
TABLE V Colonic biopsy scores

\begin{tabular}{ll}
\hline Time after first dose (days) & Biopsy score (mean (SEM)) \\
\hline-3 & $4 \cdot 5(0 \cdot 2)$ \\
12 & $2 \cdot 7(0 \cdot 8)^{\star}$ \\
32 & $3 \cdot 0(0 \cdot 4)^{\star}$ \\
49 & $2 \cdot 3(0 \cdot 7)^{\star}$ \\
63 & $3 \cdot 8(0 \cdot 2)$
\end{tabular}

Values are means (SEM) for six animals.

${ }^{\star} \mathrm{p}<0.05$ compared with pretreatment value (Friedman test).

value of $4.5(0.2)$ to $3(0.4)(\mathrm{p}<0.05)$. This improvement was maintained until day 49 .

\section{Discussion}

Recent advances in the understanding of the mechanisms and control of inflammation have focused on the importance of numerous cytokines in this process. TNF $\alpha$ seems to play an important role in septic shock, rheumatoid arthritis and IBD. This has been demonstrated by the raised concentrations of TNF $\alpha$ both in plasma and locally in inflamed tissues in these conditions and has led to the development of monoclonal antibodies as potential therapies in these conditions. A murine antibody to TNF $\alpha$ has been used in early phase trials in patients with septic shock ${ }^{28}$ but was associated with a significant host response to the antibody. However, antibody engineering involving either chimerisation or CDR grafting of murine monoclonal antibodies to $\mathrm{TNF} \alpha$ to reduce immunogenicity has permitted certain conditions - for example, rheumatoid arthritis, to be treated. ${ }^{12} 29$ From this background, we evaluated the use of an antibody to $\mathrm{TNF} \alpha$ in the treatment of ulcerative colitis in an animal model.

Previous work using chemically induced colonic inflammation in rats $^{17}$ has clearly demonstrated the ability of anti-murine TNF $\alpha$ to modulate the inflammatory response; however, the initial dose was given prior to the induction of inflammation. In ulcerative colitis in humans, treatment is required once disease is diagnosed and often the disease process may be longstanding before treatment is instituted.

Spontaneous ulcerative colitis in the cottontop tamarin provides a good model for evaluating new treatments for established disease in circumstances more related to the clinical situation. All animals recruited to this study had not received any previous treatment and the anti-TNF $\alpha$ was the sole treatment used. Based on the knowledge of pharmacokinetics of CDP571 and the lack of a deleterious immune response, we administered the antibody safely on a total of six occasions over six weeks. By comparison, Podolsky et $a l,{ }^{23}$ using a murine monoclonal antibody to $\alpha 4$ integrin to treat colitis in the cottontop tamarin, was restricted to therapy at two day intervals over 10 days because of the host immune response to the antibody. In this study, all animals demonstrated a rapid improvement after administration of anti-TNF $\alpha$ with an increase in body weight, an improvement in the consistency of stools and in rectal 
biopsy score. The response, which occurred as early as the first injection, was far more rapid than that seen to an established therapeutic regime based on the 5-aminosalycyclic acid compound olsalazine. ${ }^{19}$ 5-Aminosalicylic acid based treatment is standard for ulcerative colitis in humans and has been used successfully to treat ulcerative colitis in the tamarin. However, when starting treatment there must be a gradual increase in dose levels. Improvement in rectal biopsy pathology and in clinical condition may not be seen for eight to 10 weeks in tamarins.

There were no placebo treated control animals in this study. The cottontop tamarin is listed under CITES as an endangered species and as such it was felt unethical to withhold therapy from animals with ulcerative colitis. Furthermore, it is known from previous studies in the colony that if animals are not treated the disease progresses unabated with progressive weight loss and deterioration of clinical condition leading either to death or euthanasia. Reference to colony records for six animals with confirmed ulcerative colitis that were not receiving therapy and were monitored over four weeks revealed an increase in mean rectal biopsy score from 1.3 to 2.6 over this period, indicating a deterioration in pathology.

Of the six animals that were recruited to the study, the majority $(4 / 6)$ have not required any further treatment 18 months after the last dose. Two animals did, however, relapse and were given maintenance therapy with olsalazine. This occurred between eight months (R192) and one year (B213) after ceasing therapy. Prolonged benefit after a single course of therapy provides further encouragement for the use of anti-TNF $\alpha$ in the treatment of ulcerative colitis. The exact mechanism of action of anti-TNF $\alpha$ is uncertain in these animals, but it seems most likely that it inhibits the action of TNF $\alpha$ in the colon wall and so attenuates the inflammatory process.

Repeated therapy with CDP571 has been used in a small number of tamarins with ulcerative colitis which was refractory to standard therapy of olsalazine and prednisolone. Again, no adverse effects were recorded and although the animals showed some improvement in their condition, the clinical response was not as notable as that reported in this study of naive animals (unpublished observations). Human patients with rheumatoid arthritis have received repeated doses of chimeric antiTNF $\alpha$ (cA2) and although apparently safe it was noted that the interval between doses fell as the number of doses administered rose. ${ }^{30} \mathrm{By}$ comparison, CDP571, at a dose of $10 \mathrm{mg} / \mathrm{kg}$, has been given at two to three month intervals for a total of four doses in the treatment of rheumatoid arthritis. No adverse effects were noted and pharmacokinetic studies indicated no reduction in the half-life in patients. ${ }^{31}$ These data provide encouragement for repeated dosing in humans.

The potential role of anti-TNF $\alpha$ in the treatment of human ulcerative colitis is now under investigation. Engineering of antibodies can prolong the half-life in humans from a few hours to one to two weeks. ${ }^{27}$ Encouraging results have already been obtained with chimeric antibodies to TNF $\alpha$ in the treatment of Crohn's disease. ${ }^{32}$ Studies with CDP571 are now continuing in acute and chronic inflammatory conditions such as IBD, and indeed preliminary studies with a single dose of antibody in an open study have proved encouraging. ${ }^{33}$

1 Sanderson JD, Moss MT, Tizard MLV, Hermon-Taylor J. Mycobacterium paratuberculosis DNA in Crohn's Mycobacterium paratuberculosis
disease tissue. Gut 1992; 33: 890-6.

2 Wakefield AJ, Pittilo RM, Sim R, Costy SL, Stephenson JR, Dhillon AP, et al. Evidence of persistent measles virus infection in Crohn's disease. $\mathcal{f}$ Med Virol 1993; 39: 345-53.

3 Thompson NP, Montgomery SM, Pounder RE, WakefieldAJ. Is measles vaccination a risk factor for inflammatory bowel disease? Lancet 1995; 345: 1071-4.

4 Wakefield AJ, Sawyerr AM, Dhillon P, Pittilo RM, Rowles PM, Lewis AM, et al. Pathogenesis of Crohn's disease: multifocal gastrointestinal infarction. Lancet 1989; ii: 773-5.

5 Rotter JI, Yang H. Delineating the major aetiological risk factors for IBD: the genetic susceptibilities. In: factors for IBD: the genetic susceptibilities. In: Gross V, eds. Inflammatory bowel diseases. London: Gross V, eds. Inflammatory bowel
Kluwer Academic Publishers, 1993.

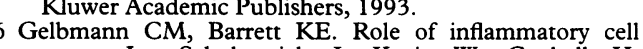
types. In: Scholmerich J, Kruis W, Goebell H, Hohenberger H, Gross V, eds. Inflammatory bowel diseases. London: Kluwer Academic Publishers, 1993.

7 Stevens C, Walz G, Singaram C, Lipman ML, Zanker B, Muggia A, et al. Tumour necrosis factor alpha, interleukin- $1 \beta$, and interleukin- 6 expression in inflammatory bowel disease. Dig Dis Sci 1992; 37: 818-26.

8 Sun X, Caplan MS, Liu Y, Hsueh W. Endotoxin-resistant mice are protected from PAF-induced bowel injury and mice are protected from PAF-induced

9 Bruin KF, Hommes DW, Jansen J, van Deventer SJM. Modulation of cytokine release from human monocytes by drugs used in the therapy of inflammatory bowel disease [abstract]. Gastroenterology 1993; 104 (suppl 4): A674.

10 Tracey KJ, Beutler B, Lowry SF, Merryweather J, Wolpe S, Milsark IW, et al. Shock and tissue injury induced by recombinant human cachectin. Science 1986; 234: 470-4.

11 Maini RN, Brennan FM, Williams R, Chu CQ, Cope AP, Gibbons D, et al. TNF $\alpha$ in rheumatoid arthritis and prospects of anti-TNF therapy. Clin Exp Rheumatol 1993; 11 (suppl 8): S173-5.

12 Elliott M, Maini RN, Feldmann M, Kalden JR, Antoni C, Smolen JS, et al. Randomised double-blind comparison of chimeric monoclonal antibody to tumour necrosis factor $\alpha$ (cA2) versus placebo in rheumatoid arthritis. factor $\alpha$ (cA2) versus place
Lancet 1994; 344: 1105-10.

13 Murch SH, Lamkin VA, Savage MO, Walker-Smith JA, MacDonald TT. Serum concentrations of tumour necrosis factor alpha in childhood chronic inflammatory bowel disease. Gut 1991; 32: 913-7.

14 Murch SH, Breagger CP, Walker-Smith JA, MacDonald TT. Location of tumour necrosis factor alpha by immunohistochemistry in chronic inflammatory bowel disease. Gut 1993; 34: 1705-9.

15 Breagger CP, Nicholls S, Murch SH, Stephens S, MacDonald TT. Tumour necrosis factor alpha in stool as a marker of intestinal inflammation. Lancet 1992; 339: 89-91.

16 Warren BF, Watkins PE. Animal models of inflammatory bowel disease. F Pathol 1994; 172: 313-6.

17 Ward PS, Woodger SR, Bodmer M, Foulkes R. Anti-tumour necrosis factor alpha monoclonal antibodies are therapeutically effective in a model of colonic inflammation. $\mathrm{Br}$ f Pharmacol 1993; 110: 77P

18 Madara J, Podolsky DK, King NW, Sehgal PK, Moore R, Winter HB. Characterization of spontaneous colitis in cottontop tamarins (Saguinus oedipus) and its response to sulfasalazine. Gastroenterology 1985; 88: 13-9.

19 Watkins PE, Warren BF, Silver IA. The treatment of ulcerative colitis in the cottontop tamarin. Abstract 726. Proceedings of 14th Congress of the International Primatological Society; 1992 Aug 16-21; Strasbourg.

20 Kirkwood JK, Pearson GR, Epstein MA. Adenocarcinoma of the large bowel and colitis in cottontop tamarins. $\mathcal{F}$ of the large bowel and colitis
Comp Pathol 1986; 96: 507-15.

21 Warren BF, Henke M, Clapp N. Extra-intestinal manifestations of cottontop tamarin colitis. In: Clapp N, ed. festations of cottontop tamarin colitis. In: Clapp $\mathrm{N}$, ed. A primate model for the study of colitis and colon
Boca Raton, FL: CRC Press, 1993: 127-32.

22 Watkins PE, Foulkes R, Ward P, Stephens S, Warren BF. Faecal tumour necrosis factor alpha in cottontop tamarin Faecal tumour necrosis factor alpha in cott
colitis [abstract]. $\mathcal{F}$ Pathol 1993; 170: $364 \mathrm{~A}$

23 Podolsky DF, Lobb R, King N, Benjamin CD, Pepinsky B, Sehgal P, et al. Attenuation of colitis in the cottontop
Sels tamarin by anti- $\alpha 4$ integrin monoclonal antibody. $\mathcal{F}$ Clin Invest 1993; 92: 372-80. 
24 Kirkwood JK, Epstein MA, Terleckei AJ. Factors influencing population growth of a colony of cottontop tamarins. Lab Anim 1983; 17: 35-41.

25 Kirkwood JK, Epstein MA, Terleckei AJ, Underwood SJ. Rearing a second generation of cottontop tamarins (Saguinus oedipus oedipus) in captivity. Lab Anim 1985; 19: 269-72.

26 Warren BF, Rigby HS, Neumann C, Hall MJ, Mountford RA Bradfield JWB. The role of multiple colonoscopic biopsies in longstanding ulcerative colitis [abstract]. $\mathcal{F}$ Pathol 1988 ; 155: $347 \mathrm{~A}$

27 Stephens S, EmtageS, Vetterlein O, Chaplin L, Bebbington C Nesbitt A, et al. Comprehensive pharmacokinetics of humanized antibody and analysis of residual antiidiotypic responses. Immunology 1995; 85: 668-74.

28 Fisher CJ, Opal SM, Dhainaut JF. Influence of anti-TNFa monoclonal antibody on cytokine levels in patients with sepsis. Crit Care Med 1993; 21: 318-27.

29 Rankin ECC, Choy EHS, Kassimos D, Kingsley GH Sopwith AM, Isenberg DA, et al. The therapeutic effects of an engineered human anti-tumour necrosis factor alph antibody (CDP571) in rhematoid arthritis. $\mathrm{Br}$ Rheumatol 1995; 34: 334-42.

30 Elliott M, Maini RN, Feldman M, Long-Fox A, Charles $\mathrm{P}$, Bijl H, et al. Repeated therapy with monoclonal antibody to tumour necrosis factor $\alpha$ (cA2) in patients with rheumatoid arthritis. Lancet 1994; 344: 1125-7.

31 Stephens S, Vetterlein O, Sopwith M. CDP571, an engineered antibody to human tumour necrosis factor. In: Antibody therapeutics. Boca Raton, FL: CRC Press, 1996.

32 van Dulleman Bijl HA, Jansen J, Tytgat GNJ, et al. Treatment of Crohn's disease with anti-tumour necrosis factor chimeric monoclonal antibody (cA2). Gastroenterology 1995; 109: 129-35.

33 Evans RC, Clark L, Rhodes JM. Treatment of ulcerative colitis with an engineered human anti-TNF $\alpha$ antibody CDP571. Proceedings of 4th United European Gastroenterology Conference; 1995 Sept 17-21; Berlin. London: BMJ Publishing Group, 1995. 